\title{
sciendo
}

\section{ENHANCING IN VITRO OOCYTE MATURATION COMPETENCE AND EMBRYO DEVELOPMENT IN FARM ANIMALS: ROLES OF VITAMIN-BASED ANTIOXIDANTS - A REVIEW}

\author{
Ayman A. Swelum ${ }^{1,2 \downarrow}$, Sameh A. Abdelnour ${ }^{3}$, Asmaa M. Sheiha ${ }^{3}$, Nesrein M. Hashem ${ }^{4}$, \\ Ayman E. Taha ${ }^{5}$, Asmaa F. Khafaga ${ }^{6}$, Youssef Attia ${ }^{7,8}$, Mohsen G. Al-Mutary ${ }^{9,13}$, Marah M. Abd El- \\ Bar $^{10}$, Husein Ohran ${ }^{11}$, Sameer A. Nagadi ${ }^{7}$, Mohamed E. Abd El-Hack ${ }^{12 *}$ \\ 'Department of Animal Production, College of Food and Agriculture Sciences, King Saud University, \\ P.O. Box 2460, Riyadh 11451, Saudi Arabia \\ ${ }^{2}$ Department of Theriogenology, Faculty of Veterinary Medicine, Zagazig University, \\ Zagazig 44511, Egypt \\ ${ }^{3}$ Department of Animal Production, Faculty of Agriculture, Zagazig University, Zagazig 44511, Egypt \\ ${ }^{4}$ Department of Animal and Fish Production, Faculty of Agriculture (El-Shatby), Alexandria University, \\ Alexandria 21545, Egypt \\ ${ }^{5}$ Department of Animal Husbandry and Animal Wealth Development, Faculty of Veterinary Medicine, \\ Alexandria University, Rasheed, Edfina 22758, Egypt \\ ${ }^{6}$ Department of Pathology, Faculty of Veterinary Medicine, Alexandria University, Edfina 22758, Egypt \\ ${ }^{7}$ Department of Agriculture, Faculty of Environmental Sciences, King Abdulaziz University, \\ 21589, Jeddah, Kingdom of Saudi Arabia \\ ${ }^{8}$ Department of Animal and Poultry Production, Faculty of Agriculture, Damanhour University, \\ Damanhour, Egypt \\ ${ }^{9}$ Department of Biology, College of Science, Imam Abdulrahman Bin Faisal University (IAU), \\ P.O. Box 1982, Dammam, 31441, Saudi Arabia \\ ${ }^{10}$ Department of Entomology, Faculty of Science, Ain Shams University, Egypt \\ ${ }^{11}$ Department of Physiology, University of Sarajevo, Veterinary Faculty, Zmaja od Bosne 90, \\ 71000 Sarajevo, Bosnia and Herzegovina \\ ${ }^{12}$ Department of Poultry, Faculty of Agriculture, Zagazig University, Zagazig 44511, Egypt \\ ${ }^{13}$ Basic and Applied Scientific Research Center, Imam Abdulrahman Bin Faisal University (IAU), \\ P.O. Box 1982, Dammam, 31441, Saudi Arabia \\ •Corresponding author: aymanswelum@zu.edu.eg; yaattia@kau.edu.sa; \\ dr.mohamed.e.abdalhaq@gmail.com
}

\begin{abstract}
Oocyte/embryo in vitro culture is one of the most important assisted reproductive technologies used as a tool for maintaining genetic resources biodiversity and the inheritance of valuable genetic resources through generations. The success of such processes affects the final goal of the in vitro culture, getting viable and healthy offspring. In common in vitro oocyte maturation and/or embryo development techniques, the development of oocytes/embryos is carried out at $5 \%$ carbon dioxide and roughly $20 \%$ atmosphere-borne oxygen ratios in cell culture incubators due to their reduced cost in comparison with low atmospheric oxygen-tension incubators. These conditions are usually accompanied by the emergence of reactive oxygen species (ROS), which can extremely damage cell membrane integrity and other vital cellular organelles, as well as genetic material. The present review mainly focuses on the antioxidant roles of different vitamins on in vitro oocyte
\end{abstract}


maturation competence and embryo development in farm animals. The use of antioxidant agents may prevent the extreme augmentation of ROS generation and enhance in vitro matured oocyte competence and embryo development. Therefore, this review aimed to provide an updated outline of the impact of antioxidant vitamin (Vit) supplementations during in vitro maturation (IVM) and in vitro fertilization (IVF) on oocyte maturation and consequent embryo development, in various domestic animal species. Thus, the enrichment of the culture media with antioxidant agents may prevent and neutralize the extreme augmentation of ROS generation and enhance the in vitro embryo production (IVEP) outcomes.

Key words: antioxidant, in vitro maturation, oocyte competence, embryo growth, animals

In vitro embryo production (IVEP) is an important technology for the generation of embryos for transfer; it comprises in vitro maturation (IVM), in vitro fertilization (IVF), intra cytoplasm sperm injection (ICSI), and somatic cell nuclear transfer. Early embryonic development, fetal growth, pregnancy, and offspring health are affected by oocyte competence (Karagouni et al., 1998). To effectively generate in vitro-produced matured oocytes and embryos, greater knowledge and enhanced IVM procedures are needed. Under normal circumstances, the physiological environment of the reproductive tract provides optimal conditions for adequate maturation and growth of oocytes and embryos. On the other hand, commercial, synthetic, in vitro media and culture conditions may not offer the same physiologic complex provided under normal, in vivo, conditions, leading to several developmental disorders (Hashem et al., 2020; Hashem and Gonzalez-Bulnes, 2020). Under normal conditions, embryos and oocytes are protected from oxidative damage by antioxidant molecules existing in oviductal and follicular fluids and by antioxidant enzyme systems such as superoxide dismutase, and glutathione peroxidase (Abdelnour et al., 2018; 2019). However, in culture conditions, oocytes and embryos are exposed to an environment lacking such sophisticated protection and tend to experience greater oxidative stress.

Oxidative damage to gametes and embryos happens due to the formation of ROS either by endogenous processes such as normal cellular metabolism or by external components such as chemicals supplied to culture media, hyperoxia, exposure to light, and other stressful factors. Thus, the antioxidant self-defense mechanism of oocytes/embryos may be not adequate to cope with the elevated levels of ROS, rising during IVM, IVF, and IVEP procedures (Chow, 1979; Rush et al., 2014). In this respect, extensive studies on the optimal conditions for in vitro culture of oocytes/ embryos have been carried out testing the efficiency of adding various hormones, vitamins, amino acids, carotenoids, fatty acids, cytokines, minerals, polyphenol compounds, and growth factors to IVM, IVF, and IVEP media (Moussa et al., 2019; Xu et al., 2018; Hashem et al., 2020). These studies highlighted the positive effects of such additives, specifically those with antioxidant activity, on oocyte maturation and in vitro embryo development through improving and maintaining cell membrane integrity, mitochondrial functions, DNA integrity, and transcription of antioxidantrelated genes (Macháty et al., 1998; Sun et al., 2001; Moussa et al., 2019; Xu et al., 2018). 
This review focuses on the scientific evidence regarding the influences of Vit supplementations on the competence of oocytes and embryo development in vitro, considering their protective and regulating roles in transcriptome gene expression, apoptosis, and mitochondrial activity.

\section{Sources of oxidative stress in culture medium and vitamin roles}

In fact, oocytes/embryos tolerance to the oxidative stress during IVEP depends on many factors related to the cell efficiency itself to scavenge ROS and the culturing media conditions. For example, maternal age and cumulus oophorus contribution, antioxidant stores, and metabolism in cells all are factors that control the ability of oocyte/embryo to tolerate oxidative stress. Also, the conditions of IVEP such as exposure to light, oxygen level, media composition are all other exogenous factors affecting redox status during the in vitro culture of oocytes/embryos. Among these, the exposure of an oocyte/embryo to high oxygen concentrations and the raised ROS greatly impacts outcomes of in vitro culture (IVC) of oocytes/embryos procedures compared with the in vivo process and is considered the main cause of cell deterioration and consequent cell function loss (Chwa et al., 2006). Thus, the main goal of challenge antioxidant addition to the culture medium is the protection of oocyte/ embryo against external and internal oxidative stress during the stages of IVM and IVF for the optimization of culture procedures.

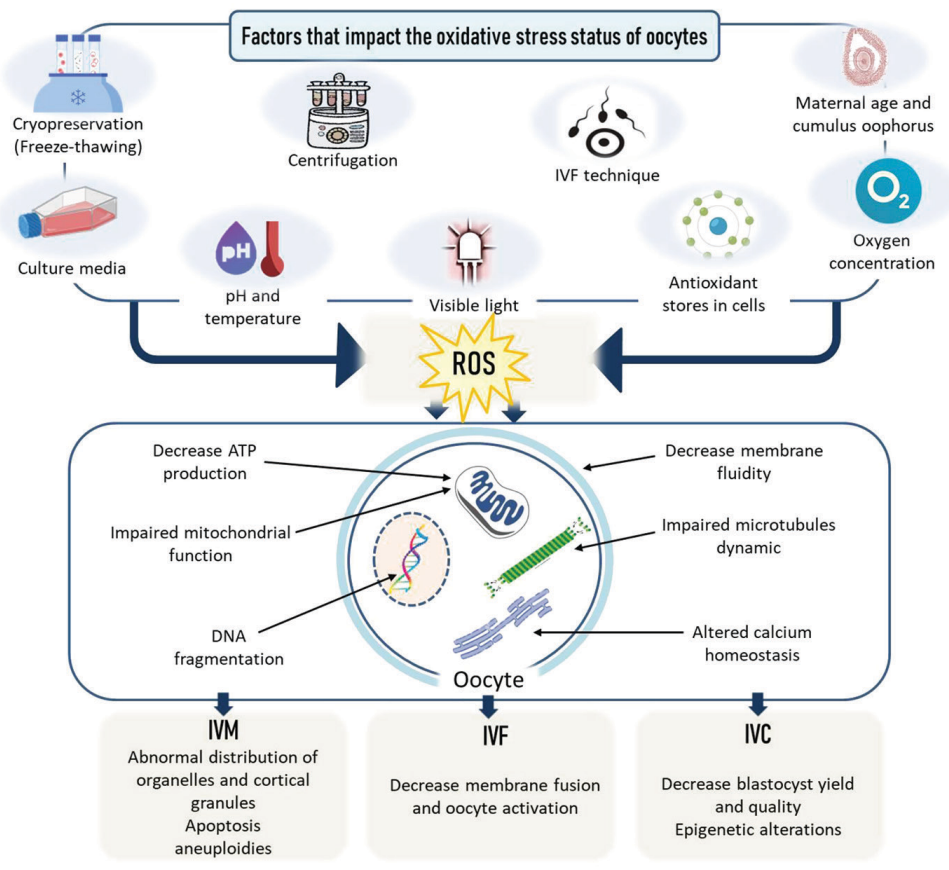

Figure 1. Factors affecting the oxidative stress status of oocyte/embryo before and during in vitro culture (IVC) and the influence of antioxidants. $\mathrm{H}_{2} \mathrm{O}_{2}=$ hydrogen peroxide, $\mathrm{O}_{2}=$ oxygen, $\mathrm{OH}=$ hydroxyl group, and $\mathrm{ROS}=$ reactive oxygen species 
Factors affecting the oxidative stress status of oocyte/embryo before and during IVC and the influence of antioxidants are illustrated in Figure 1. The effect of different antioxidant vitamins on the enhancement of in vitro matured oocyte competence and embryo development in the different animals are summarized in Table 1 and will be discussed in detail in the next sections.

Table 1. The effect of different antioxidant vitamins on the enhancement of in vitro matured oocyte competence and embryo development in different farm animals

\begin{tabular}{|c|c|c|c|c|}
\hline Item & Species & Concentration & Main findings & Reference \\
\hline 1 & 2 & 3 & 4 & 5 \\
\hline Retinoic acid & Buffalo & $5 \mathrm{nM}$ to $50 \mathrm{nM}$ & $\begin{array}{l}\text { Improves the maturation rate. } \\
\text { Conserves the transcript levels } \\
\text { of antioxidant-related genes. } \\
\text { Improves mitochondrial func- } \\
\text { tion. }\end{array}$ & (Gad et al., 2018) \\
\hline Crocin & Pig & $\begin{array}{l}400 \text { or } 500 \mu \mathrm{g} / \\
\mathrm{mL}\end{array}$ & $\begin{array}{l}\text { Enhances the maturation rate, } \\
\text { cleavage rate, GSH levels, and } \\
\text { transcription of genes related to } \\
\text { antioxidants (SOD, CAT, and } \\
\text { GPx). } \\
\text { Causes downregulation of the } \\
\text { expression of caspase- } 3 \text { and } \\
\text { apoptosis genes and decreases } \\
\text { the Bcl-2/Bax ratio. } \\
\text { Decreases the levels of ROS } \\
\text { and raises GSH levels. }\end{array}$ & $\begin{array}{l}\text { (Chen et al., } \\
\text { 2019) }\end{array}$ \\
\hline Astaxanthin & Pig & $\begin{array}{l}0 \mathrm{ppm}, 0.25 \mathrm{ppm}, \\
0.5 \mathrm{ppm}, \\
\text { or } 1 \mathrm{ppm}\end{array}$ & $\begin{array}{l}\text { Enhances the maturation of } \\
\text { oocytes and its fertilization and } \\
\text { development to the blastocyst } \\
\text { stage. } \\
\text { Decreases the proportion of } \\
\text { apoptotic oocytes exposed to } \\
\mathrm{H}_{2} \mathrm{O}_{2}(1.0 \mathrm{mM}) \text { during IVM. } \\
\text { Opposes ROS production. } \\
\text { Restores the developmental } \\
\text { competency of oocytes. }\end{array}$ & $\begin{array}{l}\text { (Abdelnour et al., } \\
2019 \text { b) }\end{array}$ \\
\hline Lycopene & Cattle & $0.2 \mu \mathrm{M}$ & $\begin{array}{l}\text { Increases the cleavage and } \\
\text { blastocyst rates. } \\
\text { Reduces ROS levels in oocytes } \\
\text { and blastocysts. } \\
\text { Reduces apoptotic nuclei in } \\
\text { embryos. } \\
\text { Attenuates the expression of } \\
\text { the IKBKB gene and reduces } \\
\text { caspase-9 and caspase-3 protein } \\
\text { abundance in embryos. } \\
\text { Upregulates the expression } \\
\text { of GDF9, BMP15, SOD2, } \\
\text { NDUFA2, ACADL, ACSL3, } \\
\text { NDUFA2, and SOD2 genes. }\end{array}$ & $\begin{array}{l}\text { (Chowdhury et } \\
\text { al., 2018) }\end{array}$ \\
\hline
\end{tabular}


Table 1 - contd.

\begin{tabular}{|c|c|c|c|c|}
\hline 1 & 2 & 3 & 4 & 5 \\
\hline \multirow[t]{2}{*}{ Vitamin E } & Sheep & $200 \mu \mathrm{M}$ & $\begin{array}{l}\text { Improves cleavage rate, moru- } \\
\text { lae and blastocyst formation, } \\
\text { and total blastocyst cell number. }\end{array}$ & $\begin{array}{l}\text { (Natarajan et al., } \\
\text { 2010) }\end{array}$ \\
\hline & Rabbit & $100 \mu \mathrm{M}$ & $\begin{array}{l}\text { Reduces apoptosis rate in cu- } \\
\text { mulus-oocyte complexes. } \\
\text { Alters mRNA transcripts linked } \\
\text { to the antioxidant response, cell } \\
\text { cycle regulation, and apoptosis } \\
\text { cascade. } \\
\text { Enhances cumulus cell expan- } \\
\text { sion and blastocyst rate. }\end{array}$ & $\begin{array}{l}\text { (Arias-Álvarez et } \\
\text { al., 2018) }\end{array}$ \\
\hline $\begin{array}{l}\text { Vitamin } B_{12} \\
\text { or cobalamin }\end{array}$ & Sheep & $200 \mathrm{pM}$ & $\begin{array}{l}\text { Increases the fertilization rate } \\
\text { and expression of DNMT1, } \\
\text { DNMT3A, and DNMT3B } \\
\text { genes in placenta. }\end{array}$ & $\begin{array}{l}\text { (Zacchini et al., } \\
\text { 2017) }\end{array}$ \\
\hline Folic acid & Goat & $\begin{array}{l}50 \mu \mathrm{M}, 100 \mu \mathrm{M} \text {, } \\
\text { or } 150 \mu \mathrm{M}\end{array}$ & $\begin{array}{l}\text { Increases the maturation of } \\
\text { oocytes and blastocyst rate. } \\
\text { Influences the expres- } \\
\text { sion of the oocyte matu- } \\
\text { ration markers (PTX3, } \\
\text { PTGS2, CTSS, and CTSSB). }\end{array}$ & $\begin{array}{l}\text { (Saini et al., } \\
\text { 2018) }\end{array}$ \\
\hline Vitamin C & Pig & $50 \mu \mathrm{g} / \mathrm{mL}$ & $\begin{array}{l}\text { Improves the competence of } \\
\text { oocyte maturation. } \\
\text { Increases BMP } 15 \text { mRNA level }\end{array}$ & $\begin{array}{l}\text { (Lin et al., 2014, } \\
\text { Yu et al., 2018) }\end{array}$ \\
\hline
\end{tabular}

GSH: glutathione, SOD: superoxide dismutase, CAT: catalase, GPx: glutathione peroxidase, ROS: reactive oxygen species, Bcl-2: cell lymphoma, 2/Bax: $B c l$-2-associated $\mathrm{X}$ protein, $\mathrm{H}_{2} \mathrm{O}_{2}$ : hydrogen peroxide, IVM: in vitro maturation, IKBKB: inhibitor of nuclear factor kappa B kinase subunit beta. GDF9: growth/differentiation factor 9, BMP15: bone morphogenetic protein 15, SOD2: superoxide dismutase 2, NDUFA2: NADH dehydrogenase [ubiquinone] 1 alpha subcomplex subunit 2, ACADL: Acyl-CoA Dehydrogenase Long Chain, ACSL3: cyl-CoA synthetase long chain family member 3, NDUFA2: NADH:ubiquinone oxidoreductase subunit A2, DNMT1: DNA (cytosine-5)-methyltransferase 1, DNMT3A: DNA methyltransferase 3 alpha, DNMT3B: DNA (cytosine-5)-methyltransferase 3 beta, PTX3: pentraxin-related protein, PTGS2: prostaglandin-Endoperoxide Synthase 2, and CTSS: cathepsin S.

\section{Fat-soluble vitamins}

\section{Vitamin A and its derivatives}

Retinoic acid

Retinoic acid (RA), which is a Vit A metabolite, plays a critical function in several physiological and pathological processes in animal organisms. Moreover, Vit A exerts an indispensable function in several animal reproductive pathways like enhancement of steroidogenesis, follicular growth, oocyte maturation improvement, and embryo development (Abdelnour et al., 2019; Hashem et al., 2016; Khafaga and El-Sayed, 2018). Retinoic acid contributes to oocyte maturation in several aspects, including transcription modifications and/or hindering the harmful influence of oxidative stress (Gad et al., 2018; Hashem et al., 2019).

Bovine follicular fluid contains high amounts of $\beta$-carotene and retinol, indicating the vital role of these vitamins in oocyte development. Several reports have 
demonstrated that media containing RA can promote the maturation rate of oocytes and significantly enhance nuclear oocyte maturation in several mammalian species. Incorporation of RA in oocyte maturation media improved oocyte maturation rate in buffalo ( $5 \mathrm{nM}$ 9-cisRA increased maturation rate of oocytes by about $10 \%$, Gad et al., 2018) and resulted in superior mitochondrial membrane potential activity, lower ROS concentration, and modified antioxidant-related gene expression in buffalo (Gad et al., 2018; Cajuday et al., 2012), goats (Conceição et al., 2016; Pu et al., 2014), and swine (Atikuzzaman et al., 2011). These enhancements could be related to the activation of the RA-inducible MAP kinase phosphatase gene, polyadenylation of mRNA in oocytes, regulation of redox signaling pathways, and gene expression of midkine (neurite growth-promoting factor 2, NEGF2) (Cajuday et al., 2012).

Despite the positive effects of RA on oocyte IVM, attention should be paid for its concentrations. The addition of high levels of RA to IVM medium may exert adverse effects on oocyte development and maturation, alters the transcription level of antioxidant-related genes, causes mitochondria dysfunction, and inhibits the immune defense of oocytes and embryos (Almiñana et al., 2008; Atikuzzaman et al., 2011; Gad et al., 2018; Gómez et al., 2003; Islam et al., 2017). The neutral or deleterious influence of high levels of retinoids developed during the IVM may be ascribed to the interaction between follicle stimulating hormone (FSH) and retinoids (Gómez et al., 2003). Moreover, it was found that RA decreases FSH and enriches the expression of luteinizing hormone (LH) receptors in porcine granulosa cells (Hattori et al., 2000). Collectively, supplementation with a low concentration (up to $50 \mathrm{nM}$ ) of RA to the IVM of oocytes increases the maturation rate through a defense mechanism that conserves acceptable antioxidant-related transcripts levels and improves mitochondrial function.

\section{Carotene derivatives}

Crocin is a water-soluble carotenoid, a derivative of deep dried red stigmas of genus Crocus blossoming plants. It has many biological and therapeutic activities, as it can act as an antioxidant, inflammatory, immunomodulatory agent, in addition to its ability to control cell proliferation and autoimmune diseases (Alaluf et al., 2002; Nalum-Naess et al., 2007; Mostafavinia et al., 2016; Gholamnezhad et al., 2013). Recently, Chen et al. (2019) evaluated the effect of crocin addition into maturation medium during porcine IVM and IVF. Supplementation with 400-500 $\mu \mathrm{g} / \mathrm{mL}$ crocin during oocyte maturation increased the maturation rate $(86.8 \%$ vs. $72.8 \%)$, cleavage rate $(62.50 \%$ vs. $53.33 \%)$, glutathione (GSH) levels, and the transcription of antioxidant-related genes such as superoxide dismutase (SOD), catalase (CAT), and glutathione peroxidase (GPx). Contrary, it significantly downregulated the expression of caspase-3 and upregulated the Bcl-2 (apoptosis suppressing factor) /Bax (apoptosis inducing factor) ratio compared with the control group. Consequently, crocin shows a crucial function in the modulation of female reproductive functions, with respect to IVM, IVF, and embryo growth. Furthermore, crocin antioxidant action diminishes oxidative stress damage through directly counteracting ROS in porcine oocyte IVM.

Astaxanthin is one of the most well-known carotenoids with antioxidant properties. In this term, Assis et al. (2014) reported that the presence of astaxanthin 
$(500 \mathrm{mM})$ in oocyte culture medium increased oocyte viability, antrum formation in the granulosa cell layer, and the total number of blastocyst cells. Moreover, astaxanthin enhanced the production of $17 \beta$-estradiol in granulosa cells, significantly reduced the level of progesterone and ROS, and apparently reduced cathepsin B activity in oocytes. (Abdelnour et al., 2019; Abdel-Ghani et al., 2019). In a study by Abdel-Ghani et al. (2019) exposing porcine oocytes to $41.0^{\circ} \mathrm{C}$ during IVM substantially obstructed fertilized oocyte maturation and development to the stage of blastocyst compared with oocytes cultured at $38.5^{\circ} \mathrm{C}$. The addition of astaxanthin $(0.5 \mathrm{ppm})$ to the maturation medium considerably enhanced oocyte maturation, fertilization, and growth to the blastocyst stage in both groups of oocytes, specifically those cultured under heat stress conditions $\left(41.0^{\circ} \mathrm{C}\right)$. The role of astaxanthin in alleviating heat stress effects is probably due to its potential to stimulate SOD activity in heat-shocked cumulus cells (Deng et al., 2008; Macháty et al., 1998; Rush et al., 2014; Sun et al., 2001).

Lycopene is another natural carotenoid derivative, which provides the red pigment of several vegetables and fruits and can be found in tomatoes, watermelons, guavas, pink grapefruits, papayas, and other fruits. One of the potential health-promoting effects of lycopene is ascribed to its ability to chemically scotch reactive oxygen species (Story et al., 2010). Interestingly, lycopene has 100-fold higher antioxidant activity than Vit E and Vit C (Mein et al., 2008). Lycopene has a high capacity to capture free radicals, furthermore, when added to culture media, it can safeguard presumed zygotes against oxidative damage, permitting embryos to overwhelm the two-cell stage block (Chowdhury et al., 2017). For example, tomatoextracted lycopene decreases peroxy radicals produced by lipid peroxidation during its propagation phase. Thus, it functions as a useful chain-breaking antioxidant that establishes carbon-centered radicals reacting extremely easily and reversibly to produce a novel chain that is a far more stable ROS than the radical peroxide itself (Chowdhury et al., 2017). Oocytes supplemented with $0.2 \mu \mathrm{M}$ lycopene had a higher percentage of cleavage (84.3\%) and blastocyst (41.0\%) development rates compared to controls (73.1 and 33.4\%, respectively). Moreover, incorporation of lycopene $(0.2$ $\mu \mathrm{M})$ into the oocyte maturation media significantly reduced the number of apoptotic nuclei (1.7 vs. 4.7) and intracellular reactive oxygen species level in oocytes and blastocysts, meanwhile the cells in the trophectoderm quantity (207.1) and mass of inner cell (41.9) increased compared to the unsupplemented group (171.3 and 36.7 respectively) (Chowdhury et al., 2018). The enhancement in cleavage and blastocyst rates may be due to the ability of lycopene to reduce the intracellular ROS levels in oocytes or blastocysts and downregulate significantly another oxidized variant such as 8-oxoguanosine, thereby presumably decreasing the DNA damage in embryos (Basu and Imrhan, 2007). Additionally, lycopene can alter the activity of some enzymes and growth factors in favor of oocyte/embryo development by decreasing the expression of the inhibitor of nuclear agent kappa B kinase, subunit beta (IKBKB), caspase-9, and caspase-3 protein abundance, while upregulating bone morphogenetic protein 15 (BMP15), growth and differentiation factor 9 (GDF9), NADH dehydrogenase (NDUFA2), superoxide dismutase 2 (SOD2), acyl-CoA synthetase 3, longchain membrane 3 (ACSL3), and acyl-CoA dehydrogenase, long chain (ACADL) (Chowdhury et al., 2018; Yao and Ye, 2008). 


\section{Vitamin $E$}

$\alpha$-tocopherol (Vit E) is a chief lipid-soluble compound, which has a potent role as an antioxidant agent in vitro and in vivo to protect cells against ROS (Rush et al., 2014; Attia et al., 2017, 2020 a). Several experiments indicated that the incorporation of $\alpha$-tocopherol into embryo culture media improved the bovine and porcine blastocyst quality and embryo development (Natarajan et al., 2010; Olson and Seidel $\mathrm{Jr}, 2000)$. The addition of $200 \mu \mathrm{M}$ Vit $\mathrm{E}$ in embryo culture medium significantly improved the rates of cleavage $(61.21 \%)$, and morulae $(27.92 \%)$ and blastocyst $(10.62 \%)$ formation, and blastocyst total cell number $(94.50 \%)$ when compared with control (59.06, 26.16, 8.9, and 88.175, respectively) (Natarajan et al., 2010). Some data illustrated that in the cultivation medium the addition of Vit E amplified ovine nuclear maturation and cleavage rates (Adeldust et al., 2015). Enrichment of culture media with Vit E enhanced granulosa cell viability (McCluskey et al., 1999), folliculogenesis, oocyte quality, fertilization rates, and in vitro early development of embryos in cattle (Olson and Seidel Jr, 2000), buffalo (Saikhun et al., 2008), sheep (Natarajan et al., 2010), and gilts (Tao et al., 2010; Tareq et al., 2012). Apparently, the blastocyst rate of somatic cell nuclear transfer (SCNT) in embryos was increased by Vit E (Jeong et al., 2006; Wongsrikeao et al., 2007) and defended oocytes during IVM against the harmful effects of cryoprotectants in vitrified ovaries (Farzollahi et al., 2016; Yashiro et al., 2015). Arias-Álvarez et al. (2018) conducted a study, which showed that the addition of $100 \mu \mathrm{M}$ Vit $\mathrm{E}$ to the maturation medium was a suitable approach to control oxidative stress and apoptosis and improve the in vitro development competence of rabbit oocytes. The encouraging influences of Vit E on oocyte maturation and embryo growth can be related to prompted alterations in mRNA transcripts linked to antioxidative response, cell cycle regulation, apoptosis cascade, and cumulus expansion (Arias-Álvarez et al., 2018). Nevertheless, numerous studies have indicated that the $\alpha$-tocopherol presence in the culture medium of oocyte maturation and embryonic pre-implantation development had no impact on bovine (Dalvit et al., 2005), buffalo (Thiyagarajan and Valivittan, 2009) and ovine nuclear maturation, fertilization, and blastocyst production rates (Natarajan et al., 2010).

\section{Vitamin $K$}

Vit $\mathrm{K}$ has three structures, which are $\mathrm{K}_{1}$ (Phylloquinone), $\mathrm{K}_{2}$ (Menaquinone) and $\mathrm{K}_{3}$ (Menadione) (Booth, 2012). One of the mechanisms for ROS creation in the body is through activation of 12-lipoxygenase, an enzyme involved in the metabolism of the arachidonic acid. Vit $\mathrm{K}$ has been observed to block the activation of 12-lipoxygenase in arachidonic acid-induced oxidative injury to developing oligodendrocytes (Li et al., 2009). Vit $\mathrm{K}_{1}$ and Vit $\mathrm{K}_{2}$ homologue called menaquinone-4 (MK-4) guard developing oligodendrocytes and immature neurons against glutathione depletion generated ROS and oxidative damage ( $\mathrm{Li}$ et al., 2003). Also, Vit K hydroquinone (KH2) was an effective bio-antioxidant; there is a shortage of knowledge on the regenerative antioxidative enzymatic mechanisms for this required trace nutrient, which could be an area of further studies (Vervoort et al., 1997; Li et al., 2003).

The addition of Vit $\mathrm{K}_{2}$ to the culture medium significantly improves in vitro produced bovine embryos. Vit $\mathrm{K}_{2}$ improves embryonic phenotype when supplied at the 
imitation of embryonic genome activation (a stage at the beginning of mitochondrial maturation, Baldoceda-Baldeon et al., 2014). In this respect, Vit $\mathrm{K}_{2}$ functions as an electron carrier and facilitates the electron transfer during the mitochondrial respiratory chain to increase the efficient oxygen use and ATP molecules production (Vos et al., 2012). Also, it may represent a hopeful drug to prevent and rescue embryonic mitochondrial dysfunctions (Cerqua et al., 2019; Ivanova et al., 2018), as the oxidative stress and ROS in IVC system could impair mitochondrial functions and thereby delay embryo development (Baldoceda-Baldeon et al., 2014), and adding Vit $\mathrm{K}_{2}$ probably rescues those embryos and restores their mitochondria functions. Therefore, the study of Baldoceda-Baldeon et al. (2014) demonstrated that the supplementation of $\mathrm{Vit}_{\mathrm{K}}$ at $0.5 \mathrm{mM}$ level after $72 \mathrm{~h}$ of fertilization of IVC culture of bovine embryo improves blastocyst rate, embryonic phenotype, and mitochondrial activity. In addition, the $0.1 \mu \mathrm{M}$ concentration of Vit $\mathrm{K}_{2}$ reduced ROS concentrations, ameliorated the gene expression of mitochondrial markers, morula and blastocyst rates, embryo survival, re-expanded and hatched blastocysts of ovine embryos when supplemented to in vitro media at day 3 to day 7 after and before vitrification (Sefid et al., 2017). The advantageous effects of Vit $\mathrm{K}_{2}$ during IVC systems might be after the embryonic genome activation time with the increasing of mitochondrial activities (Baldoceda-Baldeon et al., 2014). So, Vit $\mathrm{K}_{2}$ has important anti-oxidative properties to rescue embryonic mitochondria after genome activation from apoptosis caused by IVC stress.

\section{Vitamin D}

Vit D could be considered one of the important membrane antioxidants. Different forms of Vit $\mathrm{D}_{3}$ (cholecalciferol) and its active metabolite 1,25-dihydroxycholecalciferol, Vit $\mathrm{D}_{2}$ (ergocalciferol), and 7-dehydrocholesterol (pro-Vit $\mathrm{D}_{3}$ ) all can inhibit iron-based liposomal lipid peroxidation (Wiseman, 1993) and activate gene expression, regulating several biological processes (Norman, 2006). Vit D has a potential role in human and animal reproduction and its low levels in serum associate with a depressed fertilization rate in IVF (Rosen et al., 2012; Alagawany et al., 2020; Liu et al., 2019; Attia et al., 2020 b). Low concentration of Vit $\mathrm{D}_{3}(25 \mathrm{pg} / \mathrm{ml})$ during the IVC of secondary preantral follicles of rhesus macaques can increase their survival, whereas its high concentration $(100 \mathrm{pg} / \mathrm{ml})$ can improve antral follicle growth $(\mathrm{Xu}$ et al., 2016). On the other hand, some authors mentioned that the Vit D status of IVF patients was not linked to pregnancy rates (Fabris et al., 2014; Paffoni et al., 2014; Polyzos et al., 2014). Also, Ciepiela et al. (2018) observed a negative correlation between the level of Vit D in follicular fluid and oocyte competence, fertilization success, and pre-implantation development. Due to the conflicting opinions about the benefits of Vit D on the oocyte and embryo development in vivo, further studies can address the role of this Vit in IVEP outcomes.

\section{Water-soluble vitamins}

\section{Vitamin B}

Vitamin $B_{9}$ (folic acid)

Folic acid $\left(\right.$ Vit $\left.\mathrm{B}_{9}\right)$ is the primary factor of one-carbon metabolism (OCM) in mammalian cells. It works as a coenzyme in OCM unit transfer during the metabo- 
lism of nucleotide and amino acids. Therefore, it is unquestionably crucial for the formation of thymidylate (TMP) for DNA synthesis and methylation, which is in turn critical for post-implantation embryonic brain and nerve chord development (Sato et al., 2017; Tawatao et al., 2015). The impact of folic acid (50 $\mu \mathrm{M}, 100 \mu \mathrm{M}$, or $150 \mu \mathrm{M}$ ) supplementation on oocyte maturation marker expression, folate cycle enzymes in cumulus cells, and blastocyst development rate were investigated in goats by Saini et al. (2018) who found that the addition of $50 \mu \mathrm{M}$ folic acid to oocyte IVM media improved blastocyst rate, the expression of the oocyte maturation markers pentraxin-related protein (PTX3) and prostaglandin-endoperoxide synthase (PTGS2), levels of folate cycle genes, including ethionine adenosyltransferase 2A (MAT2A) and dihydrofolate reductase (DHFR), whereas that of cathepsin S (CTSS) was downregulated. Similarly, Huang et al. (2013) indicated that folic acid accelerates oocyte maturation by modifying the expression and phosphorylation of proteins implicated in M-phase promotion factor and protein kinase pathways, which are mitogen-activated as well as modifying the pattern of spindle and cortical granule migration.

\section{Vitamin $B_{12}$ (cobalamin)}

Vit $B_{12}$ is a cofactor of folate. Vit $B_{12}$ deficiency during pregnancy causes disorders of embryo development, including abnormal fetal brain development, intrauterine growth retardation, diminished cardiovascular development, and epigenetic defects (Deng et al., 2008; Gadhok et al., 2011; Ikeda et al., 2012; Rush et al., 2014) as well as long-lasting impairments of metabolic, cognitive, and motor functions (Pepper and Black, 2011; Rush et al., 2014) in both animals and humans. Vit $\mathrm{B}_{12}$ performs a role in cellular metabolism and is important to DNA, RNA, and protein synthesis, as well as to energy yield (Lima et al., 2017).

Treatment with folic acid and Vit $\mathrm{B}_{12}$ can affect ovarian function by increasing expression of granulosa cell genes in postpartum dairy cows (Preynat et al., 2010) and accelerating follicular development (Gagnon et al., 2015), indicating its important role in follicle development and oocyte maturation. In addition, Vit $\mathrm{B}_{12}$ is considered a source of one-carbon metabolism (OCM). This metabolic pathway is responsible for numerous cellular activities, including DNA and protein synthesis, DNA, RNA, and protein methylation, gene expression, and cell proliferation (Intakes, 1998; Molloy et al., 2009). OCM disorders result in decreased pregnancy success and restricted fetal development (Gadhok et al., 2011). Zacchini et al. (2017) investigated whether supplementation of culture media during IVM with Vit $\mathrm{B}_{12}$, a significant OCM co-factor, adjust the DNA methylation of IVEP sheep embryos and therefore ameliorates placental vasculogenesis. The authors compared embryos originating from oocytes matured in the presence of cobalamin or its absence, which were reassigned to synchronized recipient sheep. Moreover, the positive control group included conceptuses obtained from biologically mated sheep.

The addition of Vit $\mathrm{B}_{12}$ to IVM or IVF media led to a higher proportion of fertilization $(69.56 \%)$ than the one observed in the unsupplemented media $(57.91 \%)$. Furthermore, the addition of cobalamin during oocyte IVM improved the conceptuses quality, including the placenta vascularization with vessel maturation expression of 
vasculogenetic factors, and upregulated the placental levels of DNA methyltransferases (DNA (cytosine-5)-methyltransferase 1, DNMT1, DNA (cytosine-5)-methyltransferase 3A, DNMT3A, and DNA (cytosine-5)-methyltransferase 3 beta, DNMT3B). However, no significant improvement after cobalamin supplementation was recorded regarding blastocyst and/or implantation rate. Moreover, Vit $\mathrm{B}_{12}$ deficiency in female mammals during pre-conception and pregnancy periods can be an adverse agent to fertility, folliculogenesis, and embryo growth (Laanpere et al., 2010). In conclusion, cobalamin supplementation advances IVEP embryo quality during oocyte IVM. Therefore, it is recommended to include cobalamin in standard IVM media.

\section{Vitamin C (ascorbic acid)}

Vit C (L-ascorbic acid) is a water-soluble antioxidant and electron donor. Accumulating evidence indicates that ascorbic acid plays a vital role in several biological processes, specifically maintenance of redox status in different biological systems (Attia et al., 2011, 2017). It can decrease ROS by acting as a powerful antioxidant (non-enzymatic function), and as a crucial cofactor to regulate the family of ferrous ions and 2-oxoglutarate (Fe2+ and 2-OG)-dependent dioxygenases (enzymatic function) (Camarena and Wang, 2016; D'Aniello et al., 2017; Attia et al., 2020 a). In pig oocytes, Vit C can reprogram the methylation status of not only DNA and histones, but also RNA (Yu et al., 2018). The improvement of oocyte competence could be attributed to the ability of Vit $\mathrm{C}$ to increase the mRNA expression of bone morphogenetic protein 15 (BMP15), which regulates the proliferation, expansion (Lin et al., 2014), and apoptosis (Zhai et al., 2013) of cumulus cells to influence oocyte quality and succeeding development (Guo et al., 2016). Moreover, Castillo-Martín et al. (2015) suggested that the addition of Vit $C$ to culture and/or vitrification media improves survival rates of porcine blastocysts, proposing a linkage with heat shock protein 70 expressions.

\section{Conclusions}

The present review indicates the feasibility of the inclusion of antioxidant vitamins in oocytes/embryos medium as a strategy to improve outcomes of IVC of oocytes and embryos. Such supplementations can improve oocyte competence and embryo quality via different mechanisms, among these mechanisms the activation of antioxidant pathways and cell proliferation are the most effective. Further studies are needed to indicate the optimal dose and the most powerful antioxidant vitamins since their effects are dose-dependent, considering many aspects such as the technique used (IVM, IVF, ICSI, cloning), the composition of the medium, and the conditions of culture.

\section{Data availability statement}

The datasets used in this study are available in text and cited in the reference section.

\section{Ethics statement}

As a review, this section may not be applicable. 


\section{Conflict of interest}

The authors declare that the research was conducted in the absence of any commercial or financial relationships that could be construed as a potential conflict of interest.

\section{Acknowledgments}

The Deanship of Scientific Research (DSR) at King Abdulaziz University, Jeddah, Saudi Arabia has funded this project, under grant no. (FP-217-42 H). The authors acknowledged the administrative, technical, and financial support by DSR, King Abdulaziz University, Jeddah, Saudi Arabia.

\section{Author contributions}

All authors listed have made a substantial, direct, and intellectual contribution to the work, they all approved it for publication.

\section{References}

Abdel-Ghani M., Yanagawa Y., Balboula A., Sakaguchi K., Kanno C., Katagiri S., Takahashi M., N ag a no M. (2019). Astaxanthin improves the developmental competence of in vitro-grown oocytes and modifies the steroidogenesis of granulosa cells derived from bovine early antral follicles. Rep. Fert. Develop., 31: 272-281.

A bd e $1 \mathrm{n}$ o u r S.A.,A b d E 1 - H a c k M.E., K h a fag a A.F., A r if M., Tah a A.E., N or e 1 d in A.E. (2018). Stress biomarkers and proteomics alteration to thermal stress in ruminants: A review. J. Therm. Biol., 79: 120-134.

A b d e $1 \mathrm{n}$ o u r S.A.,A b d E 1 - H a c k M.E., S w e 1 u m A.A.-A., S a a d e $1 \mathrm{~d}$ in I.M.,N o r e $1 \mathrm{~d}$ in A.E., Khaf a g A.F., A l-Mutary M.G., Arif M., Hus se in E.-S.O. (2019). The usefulness of retinoic acid supplementation during in vitro oocyte maturation for the in vitro embryo production of livestock: a review. Animals, 9: 561.

A de $1 \mathrm{~d}$ u st H., Z e in o aldin i S., Kohram H., Roudb a r M.A., J o u pari M.D. (2015). In vitro maturation of ovine oocyte in a modified granulosa cells co-culture system and alpha-tocopherol supplementation: effects on nuclear maturation and cleavage. J. Anim. Sci. Technol., 57: 27.

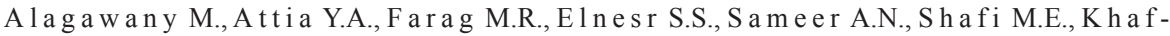
a g a A.F., O hr a n H., A l a q i 1 A.A., A b d E 1 - H a c k M.E. (2020). The strategy of boosting the immune system under the COVID-19 pandemic. Front. Vet. Sci., 7: 570748.

A l a lu f S., He in rich U., S tahl W., Tronni er H., W is e man S. (2002). Dietary carotenoids contribute to normal human skin color and UV photosensitivity. J. Nutr., 132: 399-403.

A $1 \mathrm{~m}$ iñ an a C., Gil M.A., Cu e 11 o C., Caballe ro I., Roc a J., Vazque z J.M., Go mez E., $\mathrm{M}$ a r $\mathrm{t}$ i n e $\mathrm{z}$ E.A. (2008). In vitro maturation of porcine oocytes with retinoids improves embryonic development. Rep. Fert. Develop., 20: 483-489.

Arias-Álvarez M., García-García R., López-Tello J., Rebollar P., Gutiérrez- A dán A., L or en zo P. (2018). $\alpha$-Tocopherol modifies the expression of genes related to oxidative stress and apoptosis during in vitro maturation and enhances the developmental competence of rabbit oocytes. Rep. Fert. Develop., 30: 1728-1738.

Ass is L.C., Straliotto M.R., Engel D., Hort M.A., Dutra R.C., Bem A.F. (2014). $\beta$-Caryophyllene protects the $\mathrm{C} 6$ glioma cells against glutamate-induced excitotoxicity through the Nrf2 pathway. Neuroscience, 279: 220-231.

A t i ku zz a m an M., K o o O.J., K a n g J.T., K w o n D.K., P a r k S.J., K i m S.J., G o m e z M.N.L., Oh H.J., Hong S.G., J ang G. (2011). The 9-cis retinoic acid signaling pathway and its regulation of prostaglandin-endoperoxide synthase 2 during in vitro maturation of pig cumulus cell-oocyte complexes and effects on parthenogenetic embryo production. Biol. Reprod., 84: 1272-1281. 
A t t i a Y.A., Has s a n R.A., Tag E 1 - D in A.E., A b o u - S h e h e m a B.M. (2011). Effect of ascorbic acid or increasing metabolizable energy level with or without supplementation of some essential amino acids on productive and physiological traits of slow-growing chicks exposed to chronic heat stress. J. Anim. Phys. Anim. Nutr., 95: 744-755.

A t t i a Y.A., A 1 - Harth i M.A., E 1 - S h a fey A.S., R e hab Y.A., K i m W.K. (2017). Enhancing tolerance of broiler chickens to heat stress by supplementation with vitamin $\mathrm{E}$, vitamin $\mathrm{C}$ and/or probiotics. Ann. Anim. Sci., 17: 1-15.

A t t i a Y.A., A b ou - Shehema B., A bdellah A.A., A ly O.M., E1- N a g gar A. (2020 a). Effect of ascorbic acid and/or alpha-tocopherol supplementation on semen quality, metabolic profile, antioxidants status, and DNA of roosters exposed to heat stress. J. Anim. Plant Sci., 30: 325-335.

A t t i a Y.A., A 1- Harthi M A., E1-M a t y A., H a y u A M. (2020 b). Calcium and cholecalciferol levels on late phase-laying hens' diets: effects on productive and egg quality traits, blood biochemistry and immune responses. Front. Vet. Sci., 7: 389.

Bald oce da-Bald e on L.M., Gagné D., Vigneault C., B lond in P., Robert C. (2014). Improvement of bovine in vitro embryo production by vitamin $\mathrm{K}_{2}$ supplementation. Reproduction, 148: 489-497.

B a s u A., I m r h a n V. (2007). Tomatoes versus lycopene in oxidative stress and carcinogenesis: Conclusions from clinical trials. Euro. J. Clin. Nut., 61: 295-303.

B o o th S. (2012). Vitamin K: food composition and dietary intakes. Food Nutr. Res., 56: 5505.

C a j u d a y L.A., H e r re r a A.A., D u ra n D.H. (2012). Effect of retinoic acid on the development of water buffalo embryos in vitro. Philipp J. Vet. Anim. Sci., 38: 107-116.

C a maren a V., Wang G. (2016). The epigenetic role of vitamin C in health and disease. Cell Mol. Life Sci., 73: 1645-1658.

Castillo-Martín M., Yeste M., Soler A., Morató R., Bonet S. (2015). Addition of 1ascorbic acid to culture and vitrification media of IVF porcine blastocysts improves survival and reduces HSPA1A levels of vitrified embryos. Rep. Fert. Develop., 27: 1115-1123.

Cerqua C., Casarin A., Pierrel F., Vazquez Fonseca L., Viola G., Salviati L., Trevis s on E. (2019). Vitamin K2 cannot substitute coenzyme Q10 as electron carrier in the mitochondrial respiratory chain of mammalian cells. Sci. Rep., 9: 6553.

Chen X., Xuanm B., Xu D., Wang Q., Cheng M., Jin Y. (2019), Crocin supplementation during oocyte maturation enhances antioxidant defence and subsequent cleavage rate. Rep. Dom. Anim., 54: 300-308.

C h ow C.K. (1979). Nutritional influence on cellular antioxidant defense systems. on cellular antioxidant defense systems. Am. J. Clin. Nutr., 32: 1066-1081.

Chow dhury M.M.R., Cho i B.H., K ha n I., L e e K.L., M e s a la m A., S o n g S.H., K o ng I.K. (2017). Supplementation of lycopene in maturation media improves bovine embryo quality in vitro. Theriogenology, 103: 173-184.

Chowdhury M.M.R., Mesalam A., Khan I., Joo M.D., Lee K.L., Xu L., A frin F., K o n g I.K. (2018). Improved developmental competence in embryos treated with lycopene during in vitro culture system. Mol. Reprod. Dev., 85: 46-61.

Chw a M., A til a n o S.R., R e d d y V., J or d a n N., K i m D.W., K e n n e y M.C. (2006). Increased stress-induced generation of reactive oxygen species and apoptosis in human keratoconus fibroblasts. Invest. Ophthalmol. Vis. Sci., 247: 1902-1910.

Ciepiela P., Dulęba A.J., Kowaleczko E., Chełstowski K., Kurzawa R. (2018). Vitamin D as a follicular marker of human oocyte quality and a serum marker of in vitro fertilization outcome. J. Assisted Rep. Gen., 35: 1265-1276.

Conceição J.C.Z., Moura M.T., Ferreira-Silva J.C., Cantanhêde L.F., Chaves R.M., Li m a P.F., O liver a M.A.L. (2016). Incidence of apoptosis after retinoids and insulinlike growth factor-I (IGF-I) supplementation during goat in vitro embryo production. Zygote, 24: $808-813$.

D'Aniello C., Cermola F., Patriarca E.J. Minchiotti G. (2017). Vitamin C in stem cell biology: impact on extracellular matrix homeostasis and epigenetics. Stem Cells Int., 8936156.

Dalvit G., Llanes S.P., Descalzo A., Insani M., B e coni M., Cetica P. (2005). Effect of alpha-tocopherol and ascorbic acid on bovine oocyte in vitro maturation. Rep. Dom. Anim., 40: 93-97. 
Deng L., E 1 more C.L., Law rance A.K., Mat thews R.G., Rozen R. (2008). Methionine synthase reductase deficiency results in adverse reproductive outcomes and congenital heart defects in mice. Mol. Genet. Metab., 94: 336e42.

Fabris A., Pacheco A., Cruz M., Puente J.M., Fatemi H., Garcia-Velasco J.A. (2014). Impact of circulating levels of total and bioavailable serum vitamin D on pregnancy rate in egg donation recipients. Fertil. Steril., 102: 1608-1612.

Farzollahi M., Tayefi - Nasrabadi H., Mohammadnejad D., Abedelahi A. (2016). Supplementation of culture media with vitamin E improves mouse antral follicle maturation and embryo development from vitrified ovarian tissue. J. Obstet. Gynaecol. Res., 42: 526-535.

Gad A., A bu Hamed S., Khal if a M., A m in A., E 1 -S a y ed A., S w i e fy S.A., El-Assa S. (2018). Retinoic acid improves maturation rate and upregulates the expression of antioxidant-related genes in in vitro matured buffalo (Bubalus bubalis) oocytes. Inter. J. Vet. Sci. Med., 6: 279-285.

Gadhok A.K., Sinha M., Khunteta R., Vardey S.K., Upadhyay a C., Sharma T.K., Jha M. (2011). Serum homocysteine level and its association with folic acid and vitamin $B_{12}$ in the third trimester of pregnancies complicated with intrauterine growth restriction. Clin. Lab., 57: $933 \mathrm{e} 8$.

Gagnon A., Khan D.R., S ir ard M.-A., Girard C., La for e st J.-P., Richard F.J. (2015). Effects of intramuscular administration of folic acid and vitamin $\mathrm{B}_{12}$ on granulosa cells gene expression in postpartum dairy cows. J. Dairy Sci., 98: 7797-7809.

Ghola mnezhad Z., Koushyar H., Byrami G., B o s kabady M.H. (2013). The extract of Crocus sativus and its constituent safranal, affect serum levels of endothelin and total protein in sensitized guinea pigs. Iran J. Basic Med. Sci., 16: 1022-1026.

Gómez E., Royo L.J., Duque P., Carneiro G., Hidalgo C., Goyache F., Lorenz o P.L., A 1 vare z I., F a c a 1 N., D í e z C. (2003). 9-cis-retinoic acid during in vitro maturation improves development of the bovine oocyte and increases midkine but not IGF-I expression in cumulus-granulosa cells. Mol. Rep. Dev., 66: 247-255.

Guo J., Shi L., Gong X., Ji ang M., Y in Y., Zhang X., Yin H., Li H., Emori C., S u giu ra K., Ep pi g J.J., S u Y.-Q. (2016). Oocyte-dependent activation of MTOR in cumulus cells controls the development and survival of cumulus-oocyte complexes. J. Cell Sci., 129: 3091-3103.

H a s h e m N.M., G on z a l e z - B ulnes A. (2020) State-of-the-art and prospective of nanotechnologies for smart reproductive management of farm animals. Animals, 10: 840.

H a s h e m N.M., A b d - E $1 \mathrm{r}$ a z e k D., A b o - E l e z z Z.R., L a t i f M.G.A. (2016). Effect of vitamin $\mathrm{A}$ or $\mathrm{C}$ on physiological and reproductive response of Rahmani ewes during subtropical summer breeding season. Small Rumin. Res., 144: 313-319.

H a s h e m N.M., A b u - T or E.M., A b o - E 1 e z z Z.R., L a t if M.G.A. (2019). Relevance of antioxidant vitamin supplementation for improvement of milk production, milk quality and energy status of lactating ewes. Small Rumin. Res., 177: 153-159.

H a s h e m N.M., G on za le z - B u lne s A., S i m a l-G a n d a r a J. (2020). Polyphenols in farm animals: source of reproductive gain or waste? Antioxidants, 9: 1023.

Hattori M., Takesue K., N ishida N., Kato Y., Fujihara N. (2000). Inhibitory effect of retinoic acid on the development of immature porcine granulosa cells to mature cells. J. Mol. Endocrinol., 25: 53-61.

Huang X., Ga o S., Xi a W., Hou S., Wu K. (2013). Folic acid facilitates in vitro maturation of mouse and Xenopus laevis oocytes. Brit. J. Nutr., 109: 1389-1395.

I k e d a S., K o y a m a H., S u g i m o t o M., K u m e S. (2012). Roles of one-carbon metabolism in preimplantation period effects on short-term development and long-term programming. J. Rep. Dev., 58: $38 \mathrm{e} 43$.

Institute of Medicine, Food and Nutrition Board (1998). Dietary reference intakes: thiamin, riboflavin, niacin, vitamin $\mathrm{B}_{6}$, folate, vitamin $\mathrm{B}_{12}$, pantothenic acid, biotin, and choline. Washington $\mathrm{DC}$ : National Academy Press.

Intakes IoMSCotSEoDR (1998). Dietary reference intakes for thiamin, riboflavin, niacin, vitamin B6, folate, vitamin $\mathrm{B}_{12}$, pantothenic acid, biotin, and choline. National Academies Press, US.

I s 1 a m R., D e b G.K., K a b ir A., M ir a z F.H., N a ha r T.N., H o s s a in J., P a u 1 S. (2017). Supplementation of 9-cis retinoic acid in the in vitro maturation medium increase blastocyst development rate and quality. Asian J. Med. Biol. Res., 3: 516-520. 
Ivanova D., Zhelev Z., Getsov P., Nikolova B., Aoki I., Higashi T., Bakalova R. (2018). Vitamin K: Redox-modulation, prevention of mitochondrial dysfunction and anticancer effect. Redox Biol., 16: 352-358.

J e ong Y.W., P a r k S.W., H o s s e in M.S., K i m S., K i m J.H., L e e S.H., Kang S.K., L e e B.C., H w a n g W.S. (2006). Antiapoptotic and embryotrophic effects of alpha-tocopherol and L-ascorbic acid on porcine embryos derived from in vitro fertilization and somatic cell nuclear transfer. Theriogenology, 66: 2104-2112.

K h a fa g a A.F., E $1-\mathrm{S}$ a y e d Y.S. (2018). All-trans-retinoic acid ameliorates doxorubicin-induced cardiotoxicity: in vivo potential involvement of oxidative stress, inflammation, and apoptosis via caspase-3 and p53 down-expression. Naunyn-Schmiedeberg's Arch. Pharm., 391: 59-70.

L a a p e re M., A 1 t mä e S., S t a vreus - Evers A., Nils s on T.K., Yngve A., S a l u m e ts A. (2010). Folate-mediated one-carbon metabolism and its effect on female fertility and pregnancy viability. Nutr. Rev., 68: 99-113.

Li J., Lin J.C., Wang H., P eterson J.W., Furie B.C., Furie B., B ooth S.L., Volpe J.J., R o s e n b e r g P.A. (2003). Novel role of vitamin K in preventing oxidative injury to developing oligodendrocytes and neurons. J. Neurosci., 23: 5816-5826.

Li J., Wang H., Rosenberg P.A. (2009). Vitamin K prevents oxidative cell death by inhibiting activation of 12-lipoxygenase in developing oligodendrocytes. J. Neurosci. Res., 87: 1997-2005.

Lim a M.E., P ereira R.A., Maffi A.S., Tonellotto dos Santos J., Martin C.E., De 1 P in o F.A., L e a 1 S.D., B r a un e r C.C., C or r e a M.N. (2017). Butaphosphan and cyanocobalamin: effects on the aspiration of oocytes and in vitro embryo production in Jersey cows. Canadian J. Anim. Sci., 97: 633-639.

L in Z.L., Li Y.H., X u Y.N., Wang Q.L., N a m g o ong S., Cu i X.S., K i m N.H. (2014). Effects of growth differentiation factor 9 and bone morphogenetic protein 15 on the in vitro maturation of porcine oocytes. Reprod. Domest. Anim., 49: 219-227.

Lin ster C.L., Van S cha ft ingen E. (2007). Vitamin C. The FEBS J., 274: 1-22.

Liu X., Zhang W., Xu Y., Chu Y., Wang X., Li Q., Ma Z., Li u Z., Wan Y. (2019). Effect of vitamin D status on normal fertilization rate following in vitro fertilization. Rep. Biol. Endocrinol., 17: 59 .

M a c há ty Z., D a y B.N., P r a the r R.S. (1998). Development of early porcine embryos in vitro and in vivo. Biol. Rep., 59: 451-455.

McCluskey S., Hall M., Stanton C., Devery R. (1999). $\alpha$-tocopherol inhibits oxidative stress induced by cholestanetriol and 25-hydroxycholesterol in porcine ovarian granulosa cells. Mol. Cell. Biochem., 194: 217-225.

M e in J.R., Li a n F., Wang X. (2008). Biological activity of lycopene metabolites: implications for cancer prevention. Nutr. Rev., 66: 667-683.

Mollo y A.M., K irk e P.N., Tro end l e J.F., B u rk e H., S u t to n M., B ro d y L.C., S c o t t J.M., Mills J.L. (2009). Maternal vitamin $B_{12}$ status and risk of neural tube defects in a population with high neural tube defect prevalence and no folic Acid fortification. Pediatrics, 123: 917e23.

Mos t a favin i a S.E., Kh or a s hadizad e h M., H o s h y a r R. (2016). Antiproliferative and proapoptotic effects of crocin combined with hyperthermia on human breast cancer cells. DNA Cell Biol., 35: 340-347.

Mous s a M., Yang C.Y., Z heng H.Y., Li M.Q., Yu N.Q., Yan S.F., Hu ang J.X., Sh a ng J.H. (2019). Vitrification alters cell adhesion related genes in pre-implantation buffalo embryos: Protective role of $\beta$-mercaptoethanol. Theriogenology, 125: 317-323.

Nalum-Naess S., S liwka H.R., Partali V., Melo T.B., Naqvi K.R., Jacks on H.L., L ockw o od S.F. (2007). Hydrophilic carotenoids: Surface properties and aggregation of an astaxanthin-lysine conjugate, a rigid, long-chain, highly unsaturated and highly water-soluble tetracationic bolaamphiphile. Chem. Phys. Lip., 148: 63-69.

Natarajan R., Shankar M.B., Munusw a m y D. (2010). Effect of $\alpha$-tocopherol supplementation on in vitro maturation of sheep oocytes and in vitro development of preimplantation sheep embryos to the blastocyst stage. J. Assist. Reprod. Genet., 27: 483-490.

N o r m a n A.W. (2006). Vitamin D receptor: new assignments for an already busy receptor. Endocrinology, 147: 5542-5548. 
Ols o n S.E., S e id el Jr G.E. (2000). Culture of in vitro-produced bovine embryos with vitamin E improves development in vitro and after transfer to recipients. Biol. Rep., 62: 248-252.

Paffoni A., Ferrari S., Viganò P., Pagliardini L., P a pal e o E., Candiani M., Tire 1 li A., F edele L., S o mig li a n a E. (2014). Vitamin D deficiency and infertility: insights from in vitro fertilization cycles. J. Clin. Endocrin. Metab., 99: E2372-2376.

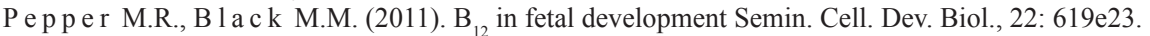

Polyzo s N.P.,A n c k a e r t E.,Guz man L.,S ch i e t t e c a t t e J.,Van L and uy t L., C a mus M., Smitz J., Tournaye H. (2014). Vitamin D deficiency and pregnancy rates in women undergoing single embryo, blastocyst stage, transfer (SET) for IVF/ICSI. Human Rep., 29: 2032-2040.

Preynat A., Lapierre H., Thivierge M.C., Palin M.F., Cardinault N., Matte J.J., Des r o chers A., Gir a r d C.L. (2010). Effects of supplementary folic acid and vitamin B (12) on hepatic metabolism of dairy cows according to methionine supply. J. Dairy Sci., 93: 2130-2142.

Pu Y., Wang Z., Bian Y., Zhang F., Yang P., Li Y., Zhang Y., Liu Y., Fang F., Cao H., Zhang X. (2014). All-transretinoic acid improves goat oocyte nuclear maturation and reduces apoptotic cumulus cells during in vitro maturation. Anim. Sci. J., 85: 833-839.

Rosen C.J., Adams J.S., Bikle D.D., Black D.M., Demay M.B., Manson J.E., Murad M.H., Kovacs C.S. (2012). The non-skeletal effects of vitamin D: an Endocrine Society scientific statement. Endocrine Rev., 33: 456-492.

Rush E.C., Katre P., Yajnik C.S. (2014). Vitamin $B_{12}$ : one carbon metabolism, fetal growth and programming for chronic disease. Eur. J. Clin. Nutr., 68: $2 \mathrm{e} 7$.

S a i khun K., F a is a ik a r m T., M ing Z., L u K.H., K it i y a n a n t Y. (2008). $\alpha$-Tocopherol and 1-ascorbic acid increase the in vitro development of IVM/IVF swamp buffalo (Bubalus bubalis) embryos. Animal, 10: 1486-1490.

S a in i S., Sh a r m a V., K u m a r A., T ha ku r A., B a j w a K., M a la k a r D. (2018). Effect of folic acid supplementation on in vitro maturation of oocytes and folate cycle. Reprod. Fert. Develop., 30: 224-225.

S a t o S., D o c h i O., I m a i K. (2017). Effect of the addition of folic acid to maturation and culture media on development of the bovine blastocyst and its survival rate after freeze-thawing. Reprod. Fert. Develop., 29: 177-177.

Sefid F., Ostadhos seini S., Hos seini S.M., Ghazvini Zadegan F., Pezhman M., $\mathrm{N}$ a s r E s fah an i M.H. (2017). Vitamin $\mathrm{K}_{2}$ improves developmental competency and cryo-tolerance of in vitro derived ovine blastocyst. Cryobiology, 77: 34-40.

Story E.N., K o p e c R.E., S chwartz S.J., H arris G.K. (2010). An update on the health effects of tomato lycopene. Annu. Rev. Food Sci. Technol., 1: 189-210.

S u n Q.Y., Wu G.M., L a i L., P a rk K.W., C a b o t R., Ch e ong H.T., D a y B.N., P r a the r R.S., $\mathrm{Sch}$ atten H. (2001). Translocation of active mitochondria during pig oocyte maturation, fertilization and early embryo development in vitro. Reproduction, 122: 155-163.

Ta o Y., Chen H., Tian N., Huo D., Li G., Zhang Y., Liu Y., Fang F., Ding J., Zhang X. (2010). Effects of L-ascorbic acid, a-tocopherol and co-culture on in vitro developmental potential of porcine cumulus cells free oocytes. Reprod. Domest. Anim., 45: 19-25.

Tareq K.M., Akter Q.S., Khandoker M.A., Tsuji i H. (2012). Selenium and vitamin E improve the in vitro maturation, fertilization and culture to blastocyst of porcine oocytes. J. Reprod. Dev., 58: 621-628.

Taw a t a o K.M., M a n a o is F.V., O c a m p o L.C., O c a m p o M.B. (2015). Folic acid supplementation for bovine oocyte maturation and fertilization in vitro. J. Agric. Tech., 11: 2401-2409.

Thiy a ga rajan B., Valivittan K. (2009). Ameliorating effect of vitamin E on in vitro development of preimplantation buffalo embryos. J. Assist. Rep. Genet., 26: 217-225.

Vervoort L.M., Ronden J.E., Thijs sen H.H. (1997). The potent antioxidant activity of the vitamin $\mathrm{K}$ cycle in microsomal lipid peroxidation. Biochem. Pharm., 54: 871-876.

Vos M., Esposito G., Ediris inghe J.N., Vilain S., Haddad D.M., Slabbaert J.R., Van Meensel S., Schaap O., De Strooper B., Meganathan R., Morais V.A., Verstreken P. (2012). Vitamin $\mathrm{K}_{2}$ is a mitochondrial electron carrier that rescues pink1 deficiency. Science, 336: 1306-1310.

W is e m a n H. (1993). Vitamin D is a membrane antioxidant Ability to inhibit iron-dependent lipid 
peroxidation in liposomes compared to cholesterol, ergosterol and tamoxifen and relevance to anticancer action. FEBS Lett., 326: 285-288.

Wongsrikea o P., Nagai T., Agung B., Taniguchi M., Kun ishi M., Suto S., Otoi T. (2007). Improvement of transgenic cloning efficiencies by culturing recipient oocytes and donor cells with antioxidant vitamins in cattle. Mol. Rep. Dev.: Incorporating Gamete Res., 74: 694-702.

X u J., B is h o p C.V., L a w s on M.S., P a r k B.S., X u F. (2016). Anti-Müllerian hormone promotes pre-antral follicle growth, but inhibits antral follicle maturation and dominant follicle selection in primates. Hum. Reprod., 31: 1522-1530.

Xu Y., Nisenblat V., Lu C., Li R., Qia o J., Zhen X., Wang S. (2018). Pretreatment with coenzyme Q10 improves ovarian response and embryo quality in low-prognosis young women with decreased ovarian reserve: a randomized controlled trial. Reprod. Biol. Endocrinol., 16: 29-33.

Ya o H., Ye J. (2008). Long chain acyl-CoA synthetase 3-mediated phosphatidylcholine synthesis is required for assembly of very low-density lipoproteins in human hepatoma huh cells. J. Biol. Chem., 283: 849-854.

Yashiro I., Tagiri M., Ogaw a H., Tas hima K., Takashima S., Hara H., Hirabayas h i M., H o c h i S. (2015). High revivability of vitrified-warmed bovine mature oocytes after recovery culture with a-tocopherol. Reproduction, 149: 347-355.

Yu X.X., Li u Y.H., Li u X.M., Wang P.C., Li u S., Mi a o J.K., Du Z.Q., Yang C.X. (2018). Ascorbic acid induces global epigenetic reprogramming to promote meiotic maturation and developmental competence of porcine oocytes. Sci. Rep., 8: 6132.

Z a c c h in i F., To s c h i P., P t a k G.E. (2017). Cobalamin supplementation during in vitro maturation improves developmental competence of sheep oocytes. Theriogenology, 93: 55-61.

Zha i B., Li u H., Li X., D a i L., G a o Y., Li C., Zhang L., D ing Y., Yu X., Zhang J. (2013). BMP15 prevents cumulus cell apoptosis through CCL2 and FBN1 in porcine ovaries. Cell. Phys. Biochem., 32: 264-278.

Received: 22 II 2021

Accepted: 24 VI 2021 